\title{
Modelling the progression of pandemic influenza A (HINI) in Vietnam and the opportunities for reassortment with other influenza viruses
}

\author{
Maciej F Boni ${ }^{1,2,4}$, Bui Huu Manh ${ }^{1}$, Pham Quang Thai ${ }^{3}$, Jeremy Farrar ${ }^{1,4,7}$, \\ Tran Tinh Hien ${ }^{5,7}$, Nguyen Tran Hien ${ }^{3}$, Nguyen Van Kinh ${ }^{6,7}$ and \\ Peter Horby*1,4,7
}

\begin{abstract}
Address: ${ }^{1}$ Oxford University Clinical Research Unit, Vietnam, ${ }^{2}$ MRC Centre for Genomics and Global Health, University of Oxford, Oxford, UK, ${ }^{3}$ National Institute of Hygiene and Epidemiology, Hanoi, Vietnam, ${ }^{4}$ Centre for Tropical Medicine, Nuffield Department of Clinical Medicine, University of Oxford, Oxford, UK, ${ }^{5}$ Hospital for Tropical Diseases, Ho Chi Minh City, Vietnam, ${ }^{6}$ National Institute for Infectious and Tropical Diseases, Hanoi, Vietnam and ${ }^{7}$ South East Asia Infectious Disease Clinical Research Network, Vietnam

Email: Maciej F Boni - mboni@oucru.org; Bui Huu Manh - bhmanh73@gmail.com; Pham Quang Thai - pqthai@nihe.org.vn; Jeremy Farrar - jfarrar@oucru.org; Tran Tinh Hien - hientt@oucru.org; Nguyen Tran Hien - nthiennihe@vnn.vn; Nguyen Van Kinh - kinhvaac@yahoo.com; Peter Horby* - peter.horby@gmail.com

* Corresponding author
\end{abstract}

Published: 3 September 2009

BMC Medicine 2009, 7:43 doi:10.1186/174|-70/5-7-43

This article is available from: http://www.biomedcentral.com/I74I-70/5/7/43

(c) 2009 Boni et al; licensee BioMed Central Ltd.

This is an Open Access article distributed under the terms of the Creative Commons Attribution License (http://creativecommons.org/licenses/by/2.0), which permits unrestricted use, distribution, and reproduction in any medium, provided the original work is properly cited.
Received: 19 June 2009

Accepted: 3 September 2009

\begin{abstract}
Background: A novel variant of influenza $\mathrm{A}(\mathrm{HINI})$ is causing a pandemic and, although the illness is usually mild, there are concerns that its virulence could change through reassortment with other influenza viruses. This is of greater concern in parts of Southeast Asia, where the population density is high, influenza is less seasonal, human-animal contact is common and avian influenza is still endemic.

Methods: We developed an age- and spatially-structured mathematical model in order to estimate the potential impact of pandemic HINI in Vietnam and the opportunities for reassortment with animal influenza viruses. The model tracks human infection among domestic animal owners and non-owners and also estimates the numbers of animals may be exposed to infected humans.

Results: In the absence of effective interventions, the model predicts that the introduction of pandemic HINI will result in an epidemic that spreads to half of Vietnam's provinces within 57 days (interquartile range (IQR): 45-86.5) and peaks 8 I days after introduction (IQR: 62.5-I2I days). For the current published range of the $2009 \mathrm{HINI}$ influenza's basic reproductive number (I.2-3.I), we estimate a median of 410,000 cases among swine owners (IQR: 220,000-670,000) with 460,000 exposed swine (IQR: 260,000-740,000), 350,000 cases among chicken owners (IQR: 170,000-630,000) with 3.7 million exposed chickens (IQR: I.9 M-6.4 M), and 5I,000 cases among duck owners (IQR: 24,000 - 96,000), with 1.2 million exposed ducks (IQR: 0.6 M-2.I M). The median number of overall human infections in Vietnam for this range of the basic reproductive number is 6.4 million (IQR: $4.4 \mathrm{M}-8.0 \mathrm{M}$ ).

Conclusion: It is likely that, in the absence of effective interventions, the introduction of a novel HINI into a densely populated country such as Vietnam will result in a widespread epidemic. A large epidemic in a country with intense human-animal interaction and continued co-circulation of other seasonal and avian viruses would provide substantial opportunities for $\mathrm{HINI}$ to acquire new genes.
\end{abstract}




\section{Background}

In early 2009 a novel influenza A (H1N1) variant emerged which spread globally causing the first influenza pandemic in over 40 years. The dynamics and impact of this pandemic are difficult to predict, especially since the world has changed significantly in 40 years - the global population has almost doubled, more people live in cities, people travel more frequently and over longer distances. These facts will undoubtedly influence the global pattern of this pandemic, just as geographical heterogeneities will result in different local patterns [1]. More than $60 \%$ of the world's population live in low-income and lower-middle income countries, and yet, at the time of writing only, about $10 \%$ of confirmed cases have occurred in these areas [2,3]. In densely populated low-income countries, where public health systems, health care services and drug availability are all stretched, influenza $\mathrm{H} 1 \mathrm{~N} 1$ is likely to be almost impossible to contain resulting in a greater number of cases occurring in more vulnerable populations resulting in a less benign epidemic.

Even more worrying, almost $60 \%$ of the world's human population and over $50 \%$ of the world's poultry population live in Asia, where highly pathogenic avian influenza (HPAI) maintains a foothold and seasonal influenza transmission is complex [4]. Previous pandemics have demonstrated the potential consequences of reassortment between human and animal influenza viruses. It is possible, therefore, that the new $\mathrm{H} 1 \mathrm{~N} 1$ - itself a reassortant of swine viruses that had previously reassorted with human and avian influenza - may follow a similar pattern $[5,6]$. The new H1N1 variant has already shown that it can be transmitted from humans to pigs, and we know that the H5N1 subtype is capable of infecting humans and of successfully reassorting with human seasonal influenza viruses under in vitro and in vivo experimental conditions $[7,8]$. As the population is increasing and standards of living are improving there has been an increase in livestock production and thus there is probably more contact between animals and humans than before. These contacts offer opportunities for reassortment, and, if a novel virus with the transmissibility of $\mathrm{H} 1 \mathrm{~N} 1$ and even a fraction of the virulence of $\mathrm{H} 5 \mathrm{~N} 1$ were to emerge, the consequences would be devastating.

In order to explore the potential impact of influenza A (H1N1) on a densely populated low-income country, we developed a mathematical model showing how an influenza A (H1N1) epidemic might progress in Vietnam. We used this model to estimate the frequency of contact between $\mathrm{H} 1 \mathrm{~N} 1$ infected humans and domestic animals in an attempt to quantify the opportunities for reassortment between $\mathrm{H} 1 \mathrm{~N} 1$ and animal influenza viruses.

\section{Methods \\ Mathematical model}

We developed an age-structured gravity model - where migration rates among sub-populations are balanced such that there are no changes in the sizes of the sub-populations - based on traditional susceptible exposed infectious recovered (SEIR) equations with stochastic migration and hospitalization processes [9]. The model has geographical resolution to the province level in Vietnam (64 provinces in 2007) and tracks infection and mixing in seven age groups. The incubation period was set at 1.4 days and the infectious stage was separated into four stages to mimic an infectious period that is $\Gamma$-distributed with a coefficient of variation equal to 0.5 . Mixing and infection among hosts (humans) in the model occurred at the province level and depended on the contact rates among the seven age groups, age-specific susceptibilities, province-specific age distribution and population density. The basic reproductive number, denoted by $R_{0}$, is calculated via a next generation matrix assuming at most one cross-province migration event during a single infection [10]. The $R_{0}$ value described in the text and figures is for Ho Chi Minh City and assumes that there is no migration from the city (see supplementary materials, additional file 1, for detail on the different $R_{0}$ values that can be computed for this model). The results are presented for a single case introduced in Ho Chi Minh City, as this is where the first case was confirmed on 31 May 2009. Infection among animal populations is not modelled. Model equations and details of computing the basic reproduction ratio are presented in the supplementary materials (Additional file 1).

\section{Data sources}

We used seven age groups: 0-5 years, 6-15, 16-25, 26-34, 35-49, 50-64 and 65+. Provincial level data on resident population by age class, number of public and private hospital beds, number of households, and number of households raising pigs, chickens, and ducks were derived from the General Statistics Office of Vietnam. The ageclass specific daily probability of migration between provinces was derived from a 2007 community survey conducted in northern Vietnam [unpublished data, P Horby]. This gave a mean estimate of $1.35 \%$ of the population moving between the provinces each day. This was used as the lower end of the modelled range, as it is known that populations closer to urban areas will have much higher rates of movement. The number of major and minor roads crossing provincial borders was determined from $1: 250,000$ road maps and were used to obtain a relative measure of interprovincial traffic. Internal migration by air travel was estimated using publicly available flight data from all airlines operating domestically in Vietnam. The known daily travel by air and the unknown daily travel by road were combined to form a scalable migration network 
between the provinces of Vietnam where between 1.35\% and $5.00 \%$ of the population moved between provinces on a daily basis.

\section{Transmission and natural history parameters}

Age-dependent mixing was included in the model by creating a contact matrix for seven age groups, using data from a survey of social contact patterns conducted in 2007 among 865 members of a community in one semi-rural district of northern Vietnam. Since both epidemiological and serological data are suggestive of age-dependent susceptibility to H1N1 infection, an age-dependent susceptibility term was also included $[11,12]$. This was derived using data on the age distribution of cases in the USA and data on age-dependent contact frequency from a European study [13]. We assumed no effect of season on the transmission of infection or on contact patterns, as influenza seasonality in Vietnam is not well understood, even in the northern and more temperate part of the country (unpublished data, PQ Thai).

Since reliable data on the natural history of infection with H1N1 were not available at the time of writing, we applied parameters previously estimated for seasonal influenza. We applied an incubation period with a mean of 1.4 days [14]. The mean of the $\Gamma$-distributed infectious period was varied between 3.8 days and 5.5 days [15]. The age-class specific relative probability of hospitalization was derived from data of the proportion of H1N1 cases hospitalized in Mexico and the USA. The overall hospitalization rate was varied between $0.5 \%$ and $1.5 \%$ of all cases, since reported rates of 5\%-6\% are likely to be biased by over-ascertainment of severe cases compared to mild cases. Hospitalization time was set at 5 days [16].

\section{Sensitivity analysis}

Sensitivity was tested by varying the basic reproduction ratio $(1.2-3.1)$, the duration of infection (3.8 - 5.5 days), the individual probability of cross-province migration (1.35\% - 5.00\% daily probability), the relative amount of traffic on large roads compared to small roads (one to two times), and the overall expected hospitalization in the population $(0.5 \%-1.5 \%)$. One thousand parameter combinations were sampled using Latin hypercube sampling, and sensitivity results are reported for these parameter samples [17]. The key parameter for this sensitivity analysis is $R_{0}$, the basic reproductive number. For influenza this is traditionally estimated between 1 and 3 [18-20] and the ranges reported so far for novel H1N1 have been 1.2, 1.4 to $1.6,2.0$ to 2.6 , and $<2.2$ to $3.1[11,21,22]$. For the upper band of our tested range, we used the highest estimate $\left(R_{0}\right.$ $=3.1$ ) as opposed to the highest of the upper band $95 \%$ confidence interval $\left(R_{0}=3.5\right)$.
Full details of data sources, parameter estimation and model specification are available in the supplementary materials (Additional file 1).

\section{Results}

\section{Epidemic curve and geographic spread}

Introducing a single infected case in Ho Chi Minh City, and simulating the epidemic for one year (over 1000 randomly sampled parameter sets), resulted in a median 6.4 million infections (IQR: 4.4 million - 8.0 million). In the absence of any intervention, the epidemic would reach half of Vietnam's provinces in 57 days (IQR: 45-86.5), and would peak after 81 days (IQR: 62.5-121). Seventy-seven percent of all cases and $67 \%$ of all hospitalizations occur in the 6-34 year age group. Table 1 shows the range of outputs for the model simulations.

The epidemic was dominated by the peaks in Hanoi and Ho Chi Minh City (Figure 1), Vietnam's most densely populated metropolitan areas. Both of these provinces are at least twice as densely populated as any other province in Vietnam. The interval between the 100-case point in Ho Chi Minh City and 100-case point in Hanoi is estimated to be about 29 days (IQR: 23-43), but might be doubled or tripled if a sustained social distancing campaign were able to reduce all contacts by $50 \%$. After the Hanoi wave passes, the epidemic is expected to tail off slowly as the disease spreads to less densely populated rural areas. Figure 2 shows the geographic progression of the median epidemic in Vietnam; Figure 3 shows the median epidemic peak times for all the provinces, indicating an approximate 1-month delay between peaks in the southern provinces and peaks in the northern provinces.

The epidemic in Vietnam is predicted to cause 58,000 hospitalizations (IQR: 39,000-75,000). The health care system would be severely stretched but is unlikely to be overwhelmed, except in the case of a high-R0 epidemic or increased virulence. Vietnam currently has a stockpile of approximately 1.1 million oseltamivir treatment courses (10 $75 \mathrm{mg}$ tablets) and sufficient powder to formulate another 900,000 treatment courses. This should be adequate for treatment of severe cases but for not mild cases or for prophylaxis of contacts during a widespread epidemic.

\section{Contacts between infected humans and domestic animals} Because of the slow dispersion of the epidemic into rural areas, the peak exposure of domestic pigs, ducks and chickens to infected humans occurs during the later phases of the epidemic. Figure 1A shows the estimated number of exposures of domestic animals to infected humans; the highest exposure will be among domestic chickens and the exposure of all domestic animals will 
Table I: Median, quartile and minimum - maximum values for selected outputs of one year of model simulation.

\begin{tabular}{|c|c|c|c|c|c|}
\hline Model output & Minimum & Lower quartile & Median & Upper quartile & Maximum \\
\hline Time to reach 20 -case point (days) & 9.0 & 12.0 & 14.0 & 19.0 & 39.0 \\
\hline Time to reach 100-case point (days) & 13.0 & 18.0 & 22.0 & 32.0 & 71.0 \\
\hline Time for 32 provinces to be affected (days) & 34.0 & 45.0 & 57.0 & 86.5 & 314.0 \\
\hline Time for 48 provinces to be affected (days) & 41.0 & 55.0 & 71.5 & 112.0 & > I year \\
\hline Epidemic peak point (days) & 45.0 & 62.5 & 80.8 & 121.0 & not reached \\
\hline Final epidemic size (number of cases) & 103,885 & $4,432,247$ & $6,377,555$ & $8,021,328$ & $9,796,738$ \\
\hline Cumulative number hospitalized & 594 & 38,832 & 58,165 & 74,935 & 104.976 \\
\hline Average number of new cases per day over 2 -week peak period & 1916 & 88,453 & 174,804 & 245,209 & 326,260 \\
\hline $\begin{array}{l}\text { Average number of new hospitalizations per day over 2-week peak } \\
\text { period }\end{array}$ & 9 & 779 & 1,564 & 2,238 & 3508 \\
\hline Cumulative number of cases in swine owners & 1940 & 224,208 & 410,276 & 671,703 & $1,159,291$ \\
\hline Cumulative number of cases in chicken owners & 630 & $|72,73|$ & 351,243 & 632,316 & $1,174,682$ \\
\hline Cumulative number of cases in duck owners & 160 & 23,732 & $51,|3|$ & 95,790 & 182,520 \\
\hline Number of days Hanoi hospitals running at $>150 \%$ bed capacity & 0 & 0 & 0 & 14 & 20 \\
\hline Number of days HCMC hospitals running at $>150 \%$ bed capacity & 0 & 0 & 0 & 0 & 11 \\
\hline Time from 100 -case point in $\mathrm{HCMC}$ to 100 -case point in Hanoi & 12 & 23 & 29 & 43 & 156 \\
\hline Number of rural cases & 16,105 & 963,791 & $1,540,008$ & $2,184,359$ & $3,220,171$ \\
\hline Number of urban cases & 87,780 & $3,440,732$ & $4,844,258$ & $5,831,431$ & $6,668,559$ \\
\hline Number of exposed pigs & 3,053 & 259,328 & 462,633 & 737,443 & $1,239,324$ \\
\hline Number of exposed chickens & 4,612 & $1,890,957$ & $3,745,045$ & $6,417,106$ & $11,419,922$ \\
\hline Number of exposed ducks & 2,319 & 580,132 & $1,176,129$ & $2,072,495$ & $3,708,187$ \\
\hline \multicolumn{6}{|l|}{ Number of infections by age group } \\
\hline 0 to 5 years & 7,611 & 366,741 & 543,858 & 685,656 & 832,651 \\
\hline 6 to 15 years & 35,370 & $1,2|1,1| 4$ & $1,617,223$ & $2,031,725$ & $2,609,789$ \\
\hline 16 to 25 years & 30,075 & $1,312,009$ & $1,837,835$ & $2,2|2,66|$ & $2,599,191$ \\
\hline 26 to 34 years & 22,277 & 998,079 & $\mathrm{I}, 450,723$ & $\mathrm{I}, 784,407$ & $2,096,515$ \\
\hline 35 to 49 years & 6,067 & 363,076 & 627,659 & 870,774 & $1,134,289$ \\
\hline 50 to 64 years & 1,920 & 130,147 & 232,582 & 329,305 & 435,306 \\
\hline
\end{tabular}


Table I: Median, quartile and minimum - maximum values for selected outputs of one year of model simulation. (Continued)

\begin{tabular}{|c|c|c|c|c|c|}
\hline 65 years and over & 565 & 38,492 & 71,658 & 106,032 & 147,498 \\
\hline \multicolumn{6}{|c|}{ Hospitalizations by age group } \\
\hline 0 to 5 years & 71 & 4,493 & 6,766 & 8,624 & 12,144 \\
\hline 6 to 15 years & 113 & 5,453 & 7,467 & 9,481 & $|3,83|$ \\
\hline 16 to 25 years & 119 & 8,128 & 11,393 & $|4,09|$ & $|8,99|$ \\
\hline 26 to 34 years & 198 & 13,580 & 19,932 & 24,989 & 33,959 \\
\hline 35 to 49 years & 81 & 5,540 & 9,424 & 13,345 & 19,910 \\
\hline 50 to 64 years & 10 & 1,284 & 2,279 & 3,310 & 5,262 \\
\hline 65 years and over & 2 & 393 & 721 & 1,079 & 1,792 \\
\hline
\end{tabular}

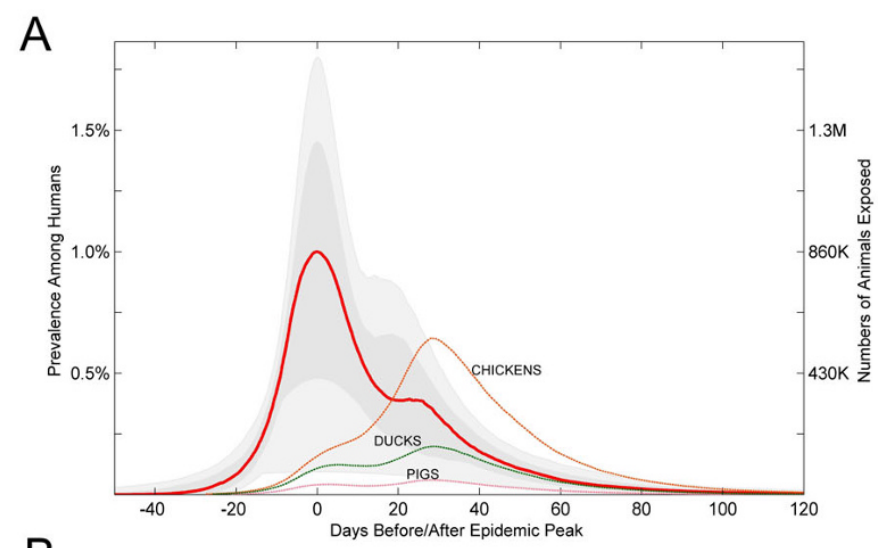

B

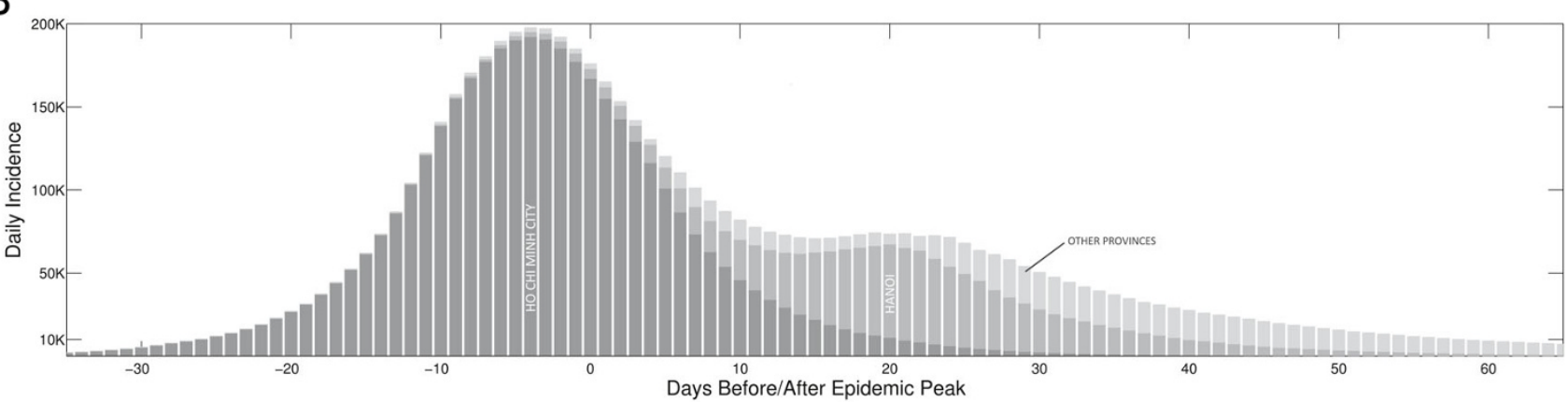

Figure I

(A) The range of possible epidemics in Vietnam. The graph summarizes 500 simulated epidemics and resets their peaks to day zero so they can be compared on the same time axis. The red line shows the median number of infected persons. The medium gray region shows the interquartile range. The light gray region shows the $95 \%$ confidence interval based on the parameter ranges chosen via Latin hypercube sampling. The confidence band width is primarily determined by $R_{0}$. The three dotted lines show the median number of exposed animals during the epidemic. (B) Median number of new cases by day, with day zero corresponding to the epidemic peak. Stacked bar graph has dark gray bars for Ho Chi Minh City, medium gray bars for Hanoi and light gray bars for the remaining 62 provinces. 


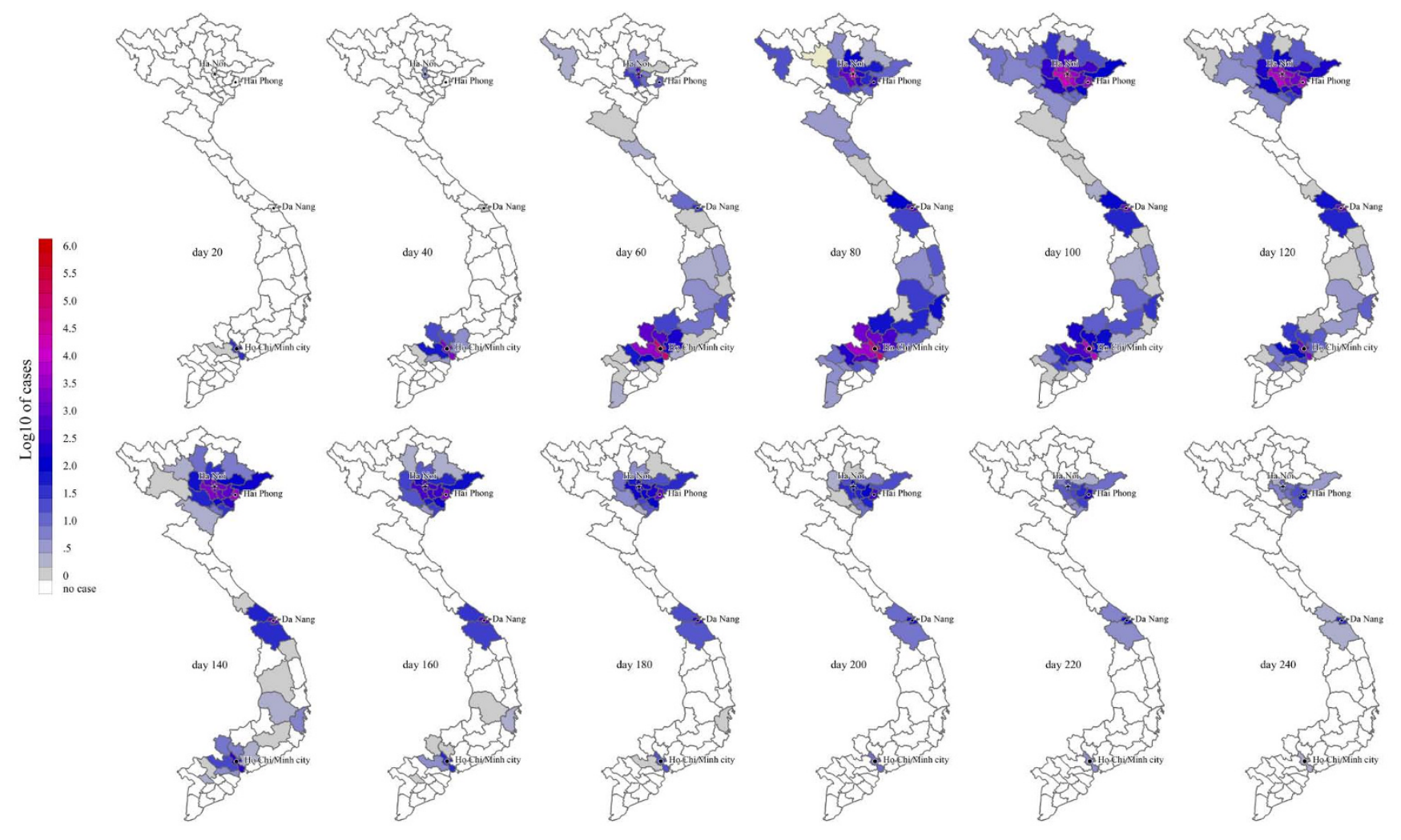

Figure 2

Geographic spread of swine-origin influenza A (HINI) in Vietnam. Case numbers in each province are medians from 1000 model simulations. See additional file 2 for corresponding animation.

peak roughly 1 month after the peak in Ho Chi Minh City and shortly after the epidemic peak in Hanoi. Note that the tail phase of the epidemic wanes slowly and that a significant number of chickens, ducks and pigs remain exposed for up to 2 months after the human epidemic has peaked in Hanoi (Figure 4).

In total, the epidemic simulations estimate a median 410,000 cases among swine owners (IQR: 220,000 670,000) with 460,000 exposed swine (IQR: 260,000$740,000)$, a median 350,000 cases among chicken owners (IQR: 170,000-630,000) with 3.7 million exposed chickens (IQR: 1.9 M-6.4 M), and a median 51,000 cases among duck owners (IQR: 24,000 - 96,000), with 1.2 million exposed ducks (IQR: 0.6 M-2.1 M).

\section{Effect of public health interventions}

By restricting contacts in the 6-15 age group, school closures were modelled but showed little effect on the progression of the epidemic. Even a comprehensive strategy of restricting all contacts within this age group would only delay the epidemic peak by a few days and result in no fewer cases. Any realistic restriction of flights between Ho Chi Minh City and Hanoi ( $<2$ weeks) had little or no effect on geographic spread or the total number of cases.
Monitoring incoming international flights and multiple introductions was not modelled.

\section{Sensitivity analysis}

Like all epidemic models, the highest sensitivity is to $R_{0}$. All severity indices of the epidemic - total number of cases, peak incidence and total number of hospitalizations - rise steadily with the $R_{0}$ value, or, in general, with the transmissibility of the virus (top panels, Figure 5). The most important feature of the model is that with increasing $R_{0}$ the epidemic becomes more rural. An increase in the predicted transmissibility of novel H1N1 in Vietnam results not only in more infections, but in a higher proportion of infection among rural populations and among those raising pigs, ducks and chickens domestically (bottom panels, Figure 5). The model is not very sensitive to the other parameters tested: the duration of the infection, the amount of migration between the provinces, the hospitalization rate or the relative amount of traffic on large roads versus small roads.

\section{Discussion}

The first cases of H1N1 were detected in Vietnam on 31 May 2009 and by mid-July there were more than 100 confirmed cases with probable community transmission that 


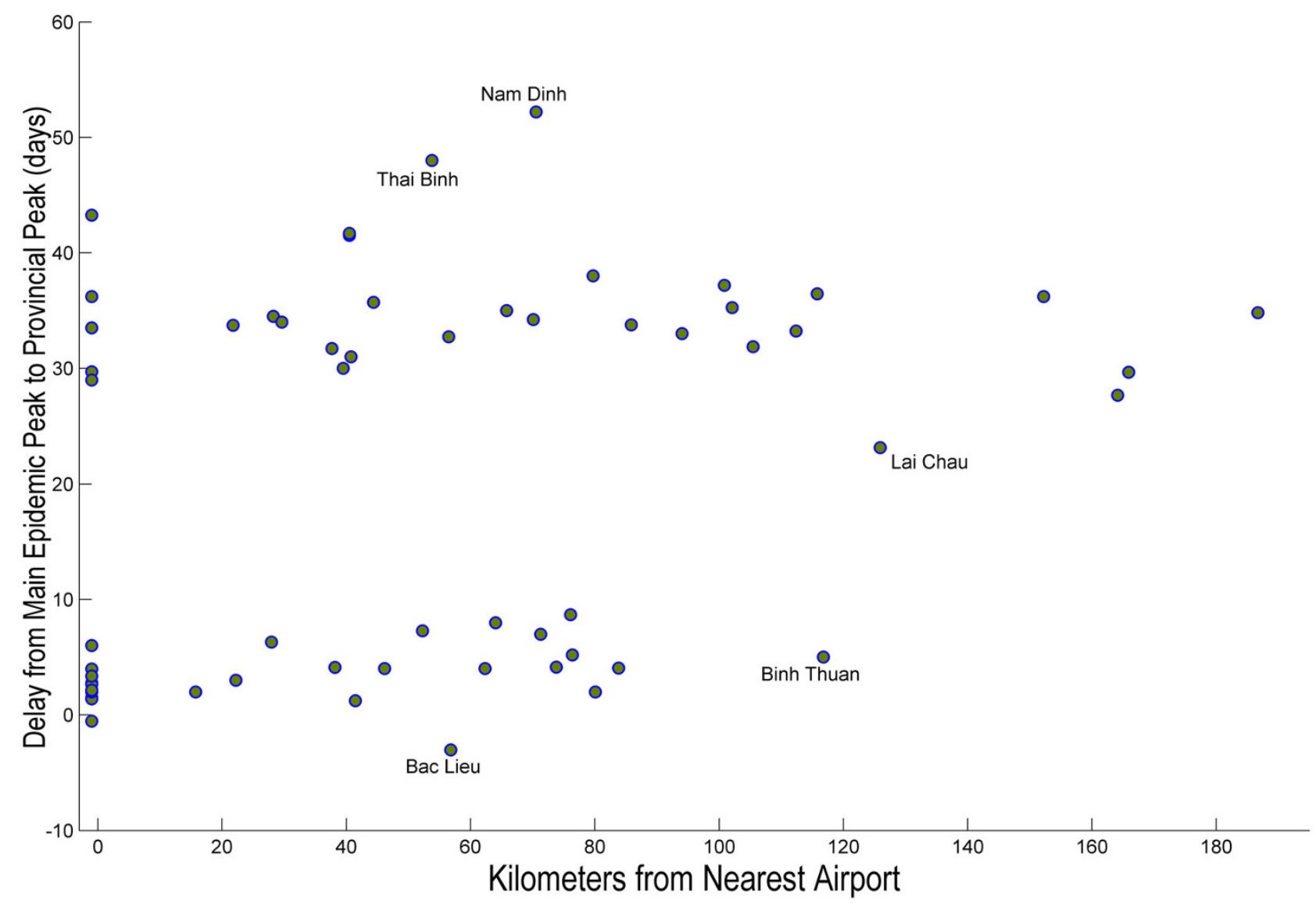

Figure 3

Timing of provincial epidemic peaks based on the distance from the nearest airport to the capital city. The model does not take sub-provincial population structure into account, and the epidemic's progression is determined primarily by south-to-north movement rather than distance to the airport network. Binh Thuan has an early peak because it lies in a densely populated part of southern Vietnam. The Lai Chau peak, as estimated by our model, probably occurs too early. Lai Chau is remote and sparsely populated, but its adjacency to the Dien Bien Phu airport causes the model to predict an early epidemic peak.

was most likely the initial budding of the coming nationwide epidemic. We have used a mathematical model to explore how the epidemic might progress in the absence of interventions and have estimated the number of pigs, ducks and chickens that might be exposed to infected humans during the epidemic. Employing mathematical modelling for such a forecasting exercise comes with many caveats. Of these, the most important are that real individuals are heterogeneous in behaviour and transmission, that human behaviour can change as a result of the severity of the epidemic and that the spatial dimensions of transmission have many nested levels that may or may not alter the progression of the epidemic on a larger scale $[23,24]$. We used a 'patch model' with coarse provincelevel spatial resolution for simplicity of model development and rapid computation; the model results should, therefore, be viewed as rough estimates of the epidemic's impact in Vietnam on a year-long time scale.
The most important caveat in our analysis is that the true basic reproductive number is not known; we used a conservative estimate, between 1.2 and 3.1, based on early measurements taken in Mexico, USA and Japan, and we stress that the $R_{0}$ for Vietnam may be higher than these estimates. For an $R_{0}$ value of 4.0 , our model predicted a total of 13.3 million cases among humans; for an $R_{0}$ value of 5.0, 16.6 million cases were predicted. Unfortunately, the uncertainty in Vietnam's $R_{0}$ will not be resolved until we analyse the progression of cases from the first wave of this pandemic.

Although the model predicts substantially more cases than have so far been reported from other H1N1 affected countries, the clinical illness is predominantly mild and, therefore, reported $\mathrm{H} 1 \mathrm{~N} 1$ cases to date reflect only a small proportion of the total number of cases. Our modelled epidemic affects a median of $7.4 \%$ of the population 

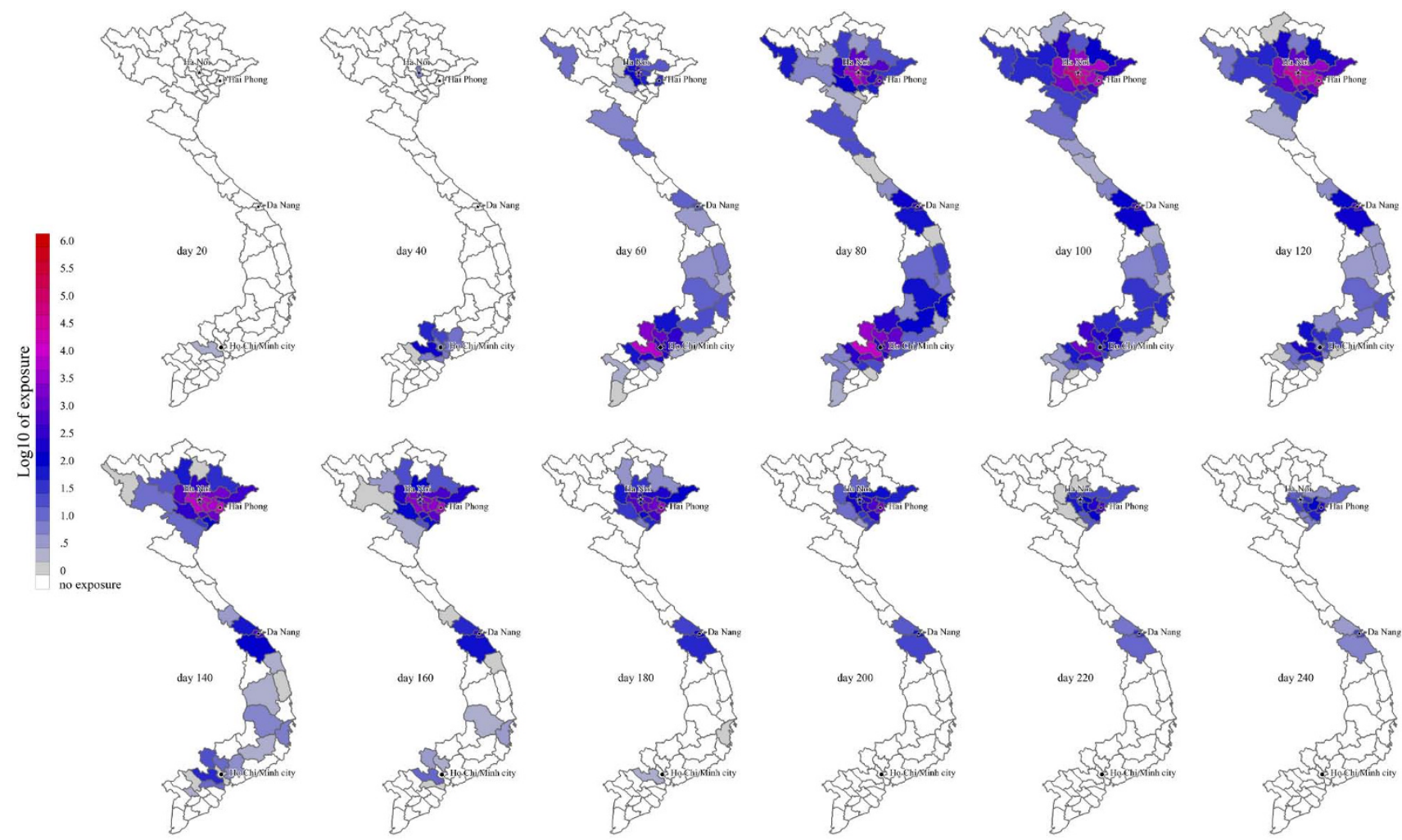

\section{Figure 4}

Geographic timeline of chicken exposure during an influenza epidemic in Vietnam. The numbers of chicken exposures are medians from 1000 models simulations. Duck and pig exposures were highly correlated with chicken exposures, geographically and temporally. Note that because of rounding and fractional cases, some sparsely-populated provinces may have a median of 0.2 human cases (rounded down to zero) and 0.8 chicken exposures (rounded up to I). See additional file 3 for corresponding animation.

(IQR: 5.2-9.3\%). This rate is below the figures for previous pandemics and might be considered too low given the high transmissibility of this virus in some settings and the expectation that most of the population would have no immunity [12]. Due to the low probability of hospitalization, it is unlikely that the health sector as a whole will be over-whelmed in the scenario outlined in this model. However, there is considerable variation in reported hospitalization rates for $\mathrm{H} 1 \mathrm{~N} 1$ and the estimate of $1 \%$ that we have used is considerably lower than the maximum of $6 \%$ [25]. As elsewhere, the number of intensive care beds is limited in Vietnam and occupancy is routinely at maximum; therefore intensive care capacity is likely to be easily overwhelmed. Also, although Vietnam has impressive health indicators for its economic status - the population may have vulnerabilities, such as under-nutrition in children, which might result in a greater number of severe cases than observed elsewhere.

Containment does appear to have been temporarily successful in some countries (Mexico and Japan) but not in others (Australia and the USA). The reasons for these differences are undoubtedly complex, but successful case detection, isolation and treatment, quarantine and chemoprophylaxis of contacts, and social distancing measures, may all have an effect on the results. In our model, school closures did not make a substantial difference to the epidemic progression, although substantial decreases in contact frequency across all age groups would delay the time course of the epidemic. School outbreaks have been a major feature in the early stages of this pandemic, and it is possible that our model underestimates the role of the range of contacts and susceptibility of school-age children on the epidemic dynamics. School closures did seem to be effective in Kobe, Japan, during 11-24 May 2009, but this may have reflected the low number of overall infections in Japan at that time (between four and 345 confirmed cases) [26]. In the UK, a plateau in consultation rates appears to have coincided with the closure of schools for the annual summer holidays [27]. Previous work suggests that school closure can modify peak attack rates and may result in a modest reduction of the final number of cases, 

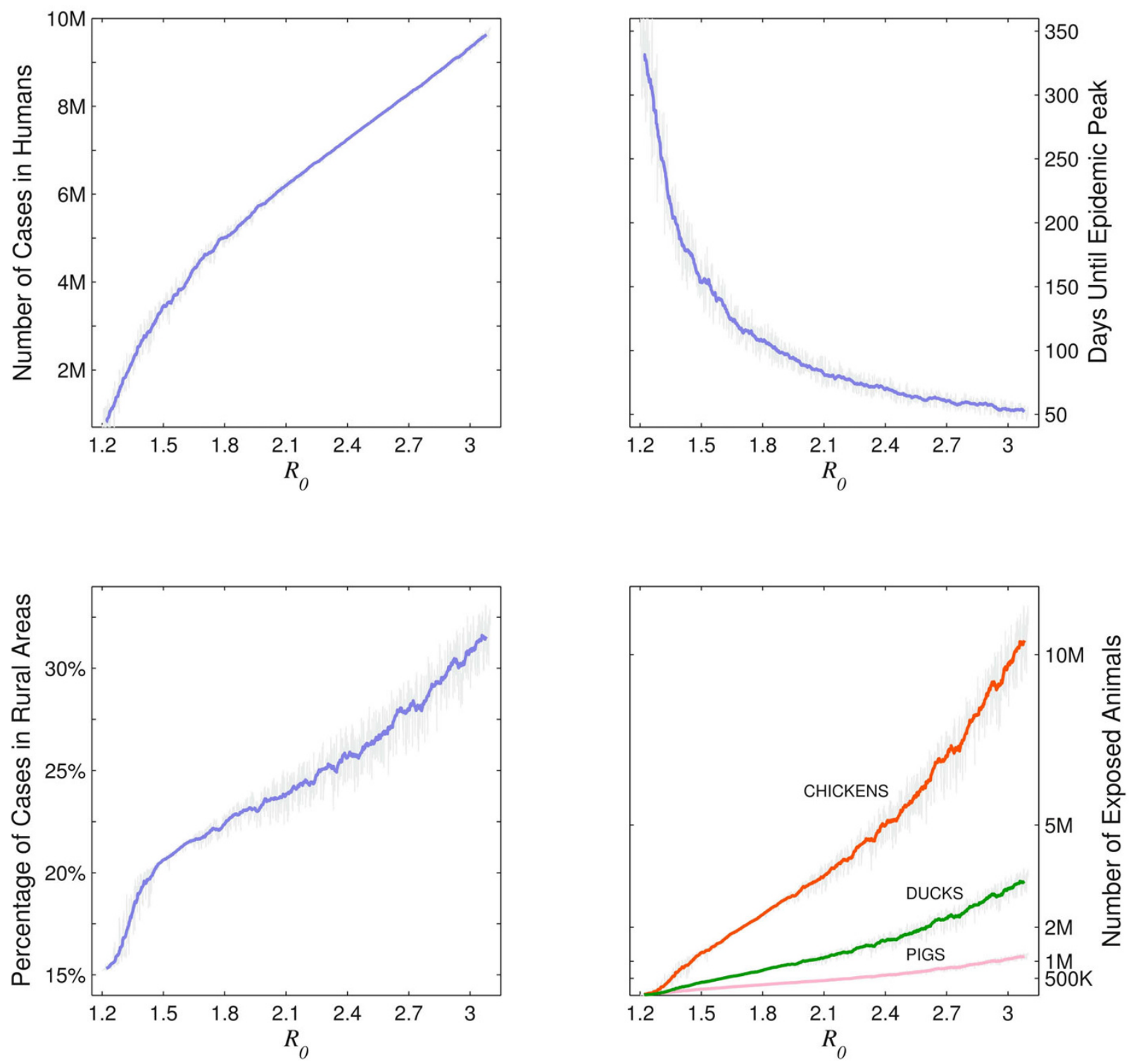

\section{Figure 5}

Result sensitivity relative to the $\boldsymbol{R}_{0}$-value as it would have been measured in Ho Chi Minh City. Light gray lines show the variation in a particular epidemiological indicator as a function of $R_{0}$. The other coloured lines are moving averages over nearby $R_{0}$-values. The top two panels show the size of the epidemic and the time taken for it to peak, which always have a predictable relationship to $R_{0}$. The bottom two panels show how animal exposure increases and how the epidemic becomes more rural as $R_{0}$ increases. Note that with higher $R_{0}$, not only does the risk to domestic animal owners increase but the relative risk of an owner to a non-owner also increases (not shown). 
but empiric data is still required on the effectiveness of school closure on reducing the number of transmissions [28-31]. Climate and other seasonally variable factors may also have acted to limit transmission in temperate regions $[32,33]$. Seasonal factors are likely to have less influence in tropical regions where the seasonality of influenza transmission is much less marked [4].

In the absence of effective interventions, we predict a large amount of contact between infected humans and animals that might harbour other influenza viruses, including HPAI. In fact, we believe our model probably underestimates the amount of contact between infected human and animals for three reasons. First, we divided the total number of human cases by the number of people per household in order to derive an estimate of the number of households with an infectious case. We did this to avoid over counting animals that were exposed to multiple infected individuals in the same household, but this is a very conservative correction. Second, domestic animal production is concentrated close to urban centres, where population densities are higher than average. Third, we did not model contacts which occurring in live poultry markets or commercial farms.

The danger of human-animal contact lies in the opportunity for reassortment among different influenza subtypes. It is well known that influenza reassorts in humans [34], that pigs play an important role in reassortment of human/avian/swine influenza viruses [35-37] and that the history of avian influenza viruses includes multiple reassortment events $[38,39]$. However, very little is known about the potential of human influenza viruses to jump to animals, since most studies to date have focused on animal influenza activity and the risk it poses to humans [4042]. Pandemic H1N1 has already been detected in swine and, since poultry and swine populations in Asia may harbour many different subtypes of influenza (at least $\mathrm{H} 4$, $\mathrm{H} 5, \mathrm{H} 6, \mathrm{H} 7, \mathrm{H} 9, \mathrm{H} 11, \mathrm{H} 12$ ), the generation of a new subtype through a reassortment event is a real possibility $[43,44]$ [personal communication, Ken Inui].

Although these opportunities for genetic reassortment are not unique, the current influenza landscape contains worrying features. Widespread epidemics of novel $\mathrm{H} 1 \mathrm{~N} 1$ are likely in tropical countries where HPAI is endemic and seasonal influenza transmission is complex and sustained, without the seasonal bottlenecks that characterize transmission in temperate regions [4,33]. The overall diversity of influenza viruses in southeastern Asia ensures that an epidemic of the novel H1N1 will create many opportunities for co-infection with other subtypes circulating in the region. Genetic and antigenic data suggest that Asia is a key source of influenza viruses that cause sea- sonal outbreaks in the northern and southern hemispheres [45]. This region, therefore, possesses the conditions necessary for the genesis and dissemination of new influenza variants $[33,45]$. Finally, the introduction of H1N1 into southeastern Asia creates an optimal evolutionarily environment for the virus, where re-assortment is neither too frequent nor too rare [46]. This means the virus receives the benefits of limited reassortment (a genetic novelty) but not the penalty of high levels of reassortment (the breaking apart of beneficial gene combinations).

Our model provides a rough picture of what might happen in Vietnam, but it includes many assumptions, uncertainties and un-modelled heterogeneities which require that the results be interpreted with caution. Although changes in human demography and migration over the past 40 years may make a pandemic more difficult to control, the same period has seen massive advances in technology and communication that allow us to monitor and predict this pandemic as never before. Mathematical models are one tool, but a criticism of these models is that the predictions are not subsequently tested against real outbreak data [47]. Our model development has coincided with the arrival of H1N1 in Vietnam and we are planning to track the progression of the outbreak in Vietnam in an attempt at real-time model validation and diagnostics.

\section{Abbreviations}

IQR: interquartile range; HPAI: highly pathogenic avian influenza; SEIR: susceptible exposed infections recovered.

\section{Competing interests}

The authors declare that they have no competing interests.

\section{Authors' contributions}

PH and MFB conceived the study and designed the model structure. PH, BHM, PQT and MFB collated the data and model parameters. MFB wrote the model code and ran the model and sensitivity analysis. BHM prepared all maps and video sequences. TTH, NTH, NVK and JF provided data and advised on the model design. PH and MFB wrote the first draft of the paper. All the authors reviewed and edited drafts of the manuscript and approved the final version. $\mathrm{PH}, \mathrm{BHM}, \mathrm{MFB}$ contributed equally.

\section{Additional material}

\section{Additional file 1}

Supplementary materials. Describes details of model construction, data sources, parameter estimation, $\mathrm{R}_{0}$ calculation, and sensitivity analysis. Click here for file

[http://www.biomedcentral.com/content/supplementary/17417015-7-43-S1.pdf] 


\section{Additional file 2}

Geographic spread of swine-origin influenza A (H1N1) in Vietnam. Animated GIF file that shows the full day-by-day epidemic shown in Figure 2.

Click here for file

[http://www.biomedcentral.com/content/supplementary/17417015-7-43-S2.gif]

\section{Additional file 3}

Geographic timeline of chicken exposure during an influenza epidemic in Vietnam. Animated GIF file that shows the full day-by-day exposure of chickens to human influenza infections shown in Figure 4.

Click here for file

[http://www.biomedcentral.com/content/supplementary/17417015-7-43-S3.gif]

\section{Acknowledgements}

We are grateful to the Ministry of Health of the Socialist Republic of Vietnam for their continued support for our work and to the staff of the National Institute for Infectious and Tropical Diseases, the National Institute of Hygiene and Epidemiology, and the Hospital for Tropical Diseases for their dedication to high quality research into infectious diseases in Vietnam. This work was supported by the Wellcome Trust UK (grants 081613/ Z/06/Z and 077078/Z/05/Z) and the South East Asia Infectious Disease Clinical Research Network (NOI-A0-50042). Model simulations were run at the computing facilities of the Wellcome Trust Sanger Institute. We also thank Ms Ho Thi Nhan for gathering the domestic flight information for Vietnam. MFB is funded by a UK Medical Research Council grant G06007I 8 to Dominic Kwiatkowski.

\section{References}

I. Miller MA, Viboud C, Balinska M, Simonsen L: The signature features of influenza pandemics - implications for policy. N Engl J Med 2009, 360:2595-2598.

2. World_Bank: World Development Indicators database. 2009.

3. Influenza $\mathbf{A}(\mathbf{H I N I})$ - update 58 [http://www.who.int/csr/don/ 200907 06/en/index.html]. accessed July 6, 2009

4. Viboud C, Alonso W], Simonsen L: Influenza in tropical regions. PLoS Med 2006, 3(4):e89.

5. Garten RJ, Davis CT, Russell CA, Shu B, Lindstrom S, Balish A, Sessions WM, Xu X, Skepner E, Deyde V, Okomo-Adhiambo A, Gubareva L, Barnes J, Smith CB, Emery SL, Hillman MJ, Rivailler P, Smagala J, de Graaf M, Burke DF, Fouchier RAM, Pappas C, AlpucheAranda CM, Lopez-Gatell H, Olivera H, Lopez I, Myers CA, Faix D, Blair PJ, Yu C, Keene KM, Dotson PD Jr, Boxrud D, Sambol AR, Abid SH, St George K, Bannerman T, Moore AL, Stringer DJ, Blevins P, Demmler-Harrison G], Ginsberg M, Kriner P, Waterman S, Smole S, Guevara HF, Belongia EA, Clark PA, Beatrice ST, Donis R, Katz J, Finelli L, Bridges CB, Shaw M, Jernigan DB, Uyeki TM, Smith DJ, Klimov Al, Cox NJ: Antigenic and Genetic Characteristics of Swine-Origin 2009 A(HINI) Influenza Viruses Circulating in Humans. Science 2009, 325(5937):197-20I.

6. Trifonov V, Khiabanian H, Rabadan R: Geographic dependence, surveillance, and origins of the 2009 influenza A (HINI) virus. N Engl ] Med 2009, 36I: I I5-119.

7. Jackson S, Van Hoeven N, Chen LM, Maines TR, Cox NJ, Katz JM, Donis RO: Reassortment between avian H5NI and human H3N2 influenza viruses in ferrets: a public health risk assessment. J Virol 2009, 83(16):8।31-40.

8. An Alberta swine herd investigated for HIN I flu virus [http:/ /www.inspection.gc.ca/english/corpaffr/newcom/2009/ 20090502e.shtml]

9. Heesterbeek ODaJAP: Mathematical Epidemiology of Infectious Diseases: Model Building, Analysis, and Interpretation. Chichester: John Wiley \& Sons Ltd; 2000.
10. Diekmann O, Heesterbeek JA, Metz JA: On the definition and the computation of the basic reproduction ratio $\mathrm{RO}$ in models for infectious diseases in heterogeneous populations. J Math Biol 1990, 28(4):365-382.

11. Fraser C, Donnelly CA, Cauchemez S, Hanage WP, Van Kerkhove MD, Hollingsworth TD, Griffin J, Baggaley RF, Jenkins HE, Lyons EJ, Jombart T, Hinsley WR, Grassly NC, Balloux F, Ghani AC, Ferguson NM, Rambaut A, Pybus OG, Lopez-Gatell H, Alpuche-Aranda CM, Bojorquez Chapela I, Palacios Zavala E, Espejo Guevara DM, Checchi F, Garcia E, Hugonnet S, Roth C, The WHO Rapid Pandemic Assessment Collaboration: Pandemic Potential of a strain of influenza A (HINI): early findings. Science 2009, 324(5934): I557-I56I.

12. Serum cross-reactive antibody response to a novel influenza A (HINI) virus after vaccination with seasonal influenza vaccine. MMWR Morb Mortal Wkly Rep 2009, 58(19):52I-524.

13. Mossong J, Hens N, Jit M, Beutels P, Auranen K, Mikolajczyk R, Massari M, Salmaso S, Tomba GS, Wallinga J, Heijne J, Sadkowska-Todys M, Rosinska M, Edmunds W]: Social contacts and mixing patterns relevant to the spread of infectious diseases. PLOS Med 2008, 5(3):e74.

14. Lessler J, Reich NG, Brookmeyer R, Perl TM, Nelson KE, Cummings $D A$ : Incubation periods of acute respiratory viral infections: a systematic review. Lancet Infect Dis 2009, 9(5):29|-300.

15. Cauchemez S, Carrat F, Viboud C, Valleron AJ, Boelle PY: A Bayesian MCMC approach to study transmission of influenza: application to household Iongitudinal data. Stat Med 2004, 23(22):3469-3487.

16. Hospitalized patients with novel influenza $A$ (HINI) virus infection - California, April-May, 2009. MMWR Morb Mortal Wkly Rep 2009, 58(19):536-54I.

17. Blower SM, Dowlatabadi H: Sensitivity and uncertainty analysis of complex models of disease transmission: an HIV model, as an example. Int Statist Rev 1994, 62(2):229-243.

18. Chowell G, Ammon CE, Hengartner NW, Hyman JM: Estimating the reproduction number from the initial phase of the Spanish flu pandemic waves in Geneva, Switzerland. Math Biosci Eng 2007, 4(3):457-470.

19. Chowell G, Miller MA, Viboud C: Seasonal influenza in the United States, France, and Australia: transmission and prospects for control. Epidemiol Infect 2008, 136(6):852-864.

20. Mills CE, Robins JM, Lipsitch M: Transmissibility of 1918 pandemic influenza. Nature 2004, 432(70 I 9):904-906.

21. Nishiura H, Castillo-Chavez C, Safan M, Chowell G: Transmission potential of the new influenza $A(H I N I)$ virus and its age-specificity in Japan. Euro Surveill 2009, I 4(22):

22. Boelle PY, Bernillon P, Desenclos JC: A preliminary estimation of the reproduction ratio for new influenza $A(H I N I)$ from the outbreak in Mexico, March-April 2009. Euro Surveill 2009, 14(19):

23. Riley S: Large-scale spatial-transmission models of infectious disease. Science 2007, 3 16(5829): |298-|30|.

24. Watts DJ, Muhamad R, Medina DC, Dodds PS: Multiscale, resurgent epidemics in a hierarchical metapopulation model. Proc Natl Acad Sci USA 2005, I 02(32): I I I 57-I I I 62.

25. Considerations for assessing the severity of an influenza pandemic. Wkly Epidemiol Rec 2009, 84(22): 197-202.

26. Human infection with new influenza $A(H I N I)$ virus: clinical observations from a school-associated outbreak in Kobe, Japan, May 2009. Wkly Epidemiol Rec 2009, 84(24):237-244.

27. Weekly pandemic flu update - 30 July 2009 [http:// www.hpa.org.uk/webw/HPAweb\&HPAwebStandard/HPAweb C/ 1248940838384 ? $\mathrm{p}=|23| 252394302$ ]

28. Ferguson NM, Cummings DA, Fraser C, Cajka JC, Cooley PC, Burke DS: Strategies for mitigating an influenza pandemic. Nature 2006, 442(7101):448-452.

29. Glass K, Barnes B: How much would closing schools reduce transmission during an influenza pandemic? Epidemiology 2007, 18(5):623-628.

30. Cauchemez S, Valleron AJ, Boelle PY, Flahault A, Ferguson NM: Estimating the impact of school closure on influenza transmission from Sentinel data. Nature 2008, 452(7/88):750-754.

31. Cauchemez S, Ferguson NM, Wachtel C, Tegnell A, Saour G, Duncan $B$, Nicoll A: Closure of schools during an influenza pandemic. Lancet Infect Dis 2009, 9(8):473-48I. 
32. Shaman J, Kohn M: Absolute humidity modulates influenza survival, transmission, and seasonality. Proc Natl Acad Sci USA 2009, 106(9):3243-3248.

33. Rambaut A, Pybus OG, Nelson MI, Viboud C, Taubenberger JK, Holmes EC: The genomic and epidemiological dynamics of human influenza A virus. Nature 2008, 453(7195):615-619.

34. Holmes EC, Ghedin E, Miller N, Taylor J, Bao Y, St George K, Grenfell BT, Salzberg SL, Fraser CM, Lipman DJ, Taubenberger JK: Wholegenome analysis of human influenza $A$ virus reveals multiple persistent lineages and reassortment among recent $\mathrm{H}_{3} \mathrm{~N} 2$ viruses. PLoS Biol 2005, 3(9):e300.

35. Webster RG, Bean W], Gorman OT, Chambers TM, Kawaoka Y: Evolution and ecology of influenza A viruses. Microbiol Rev 1992, 56(I):152-179.

36. Brown IH, Harris PA, McCauley JW, Alexander DJ: Multiple genetic reassortment of avian and human influenza $A$ viruses in European pigs, resulting in the emergence of an $\mathrm{HIN} 2$ virus of novel genotype. J Gen Virol 1998, 79(Pt I 2):2947-2955.

37. Zhou NN, Senne DA, Landgraf JS, Swenson SL, Erickson G, Rossow K, Liu L, Yoon K, Krauss S, Webster RG: Genetic reassortment of avian, swine, and human influenza $A$ viruses in American pigs. J Virol I999, 73(10):885I-8856.

38. Chen H, Deng G, Li Z, Tian G, Li Y, Jiao P, Zhang L, Liu Z Webster $R G$, Yu K: The evolution of $\mathbf{H 5 N I}$ influenza viruses in ducks in southern China. Proc Natl Acad Sci USA 2004, I 0 I(28): 10452-10457.

39. Vijaykrishna D, Bahl J, Riley S, Duan L, Zhang JX, Chen H, Peiris JS, Smith G], Guan $Y$ : Evolutionary dynamics and emergence of panzootic H5NI influenza viruses. PLoS Pathog 2008, 4(9): $1000|6|$.

40. Pfeiffer DU, Minh PQ, Martin V, Epprecht M, Otte MJ: An analysis of the spatial and temporal patterns of highly pathogenic avian influenza occurrence in Vietnam using national surveillance data. Vet J 2007, 174(2):302-309.

41. Gilbert M, Xiao X, Pfeiffer DU, Epprecht M, Boles S, Czarnecki C, Chaitaweesub P, Kalpravidh W, Minh PQ, Otte MJ, Martin V, Slingenbergh J: Mapping H5NI highly pathogenic avian influenza risk in Southeast Asia. Proc Natl Acad Sci USA 2008, I 05(I 2):4769-4774

42. Minh PQ, Schauer B, Stevenson M, Jones G, Morris RS, Noble A: Association between human cases and poultry outbreaks of highly pathogenic avian influenza in Vietnam from 2003 to 2007: a nationwide study. Transbound Emerg Dis 2009 in press.

43. Palese P: Influenza: old and new threats. Nat Med 2004, I O(I 2 Suppl): $\$ 82-87$.

44. Jadhao SJ, Nguyen DC, Uyeki TM, Shaw M, Maines T, Rowe T, Smith C, Huynh LP, Nghiem HK, Nguyen DH, Nguyen HK, Nguyen HH Hoang LT, Nguyen T, Phuong LS, Klimov A, Tumpey TM, Cox NJ, Donis RO, Matsuoka Y, Katz JM: Genetic analysis of avian influenza $A$ viruses isolated from domestic waterfowl in live-bird markets of Hanoi, Vietnam, preceding fatal H5NI human infections in 2004. Arch Virol 2009, I54(8): | $249-6 \mid$.

45. Russell CA, Jones TC, Barr IG, Cox NJ, Garten RJ, Gregory V, Gust ID, Hampson AW, Hay AJ, Hurt AC, de Jong JC, Kelso A, Klimov Al, Kageyama T, Komadina N, Lapedes AS, Lin YP, Mosterin A, Obuchi M, Odagiri T, Osterhaus AD, Rimmelzwaan GF, Shaw MW, Skepner E, Stohr K, Tashiro M, Fouchier RA, Smith DJ: The global circulation of seasonal influenza A (H3N2) viruses. Science 2008, 320(5874):340-346.

46. Kimura M: A model of a genetic linkage system which leads to closer linkage by natural selection. Evolution 1956, I 0(3):278-287.

47. Smith DJ: Predictability and preparedness in influenza control. Science 2006, 3 I 2(5772):392-394.

\section{Pre-publication history}

The pre-publication history for this paper can be accessed here:

http://www.biomedcentral.com/1741-7015/7/43/prepub
Publish with Bio Med Central and every scientist can read your work free of charge

"BioMed Central will be the most significant development for disseminating the results of biomedical research in our lifetime. "

Sir Paul Nurse, Cancer Research UK

Your research papers will be:

- available free of charge to the entire biomedical community

- peer reviewed and published immediately upon acceptance

- cited in PubMed and archived on PubMed Central

- yours - you keep the copyright
BioMedcentral 